${ }^{3}$ C. G. Van de Walle and R. M. Martin, Mat. Res. Soc. Symp. Proc., Fall Meeting, Boston, MA, Dec. 1986 (in press).

${ }^{4}$ C. G. Van de Walle and R. M. Martin (unpublished).

${ }^{5}$ S. R. Forrest and O. K. Kim, J. Appl. Phys. 53, 5738 (1982).

${ }^{6}$ D. V. Lang, M. B. Panish, F. Capasso, J. Allan, and R. A. Hamm, Appl. Phys. Lett. 50, 736 (1987).

${ }^{7}$ R. People, Phys. Rev. B 32, 1405 (1985).

${ }^{8}$ J. C. Hensel and G. Feher, Phys. Rev. 129, 1041 (1963).

${ }^{9}$ P. Lawaetz, Phys. Rev. B 4, 3460 (1971).

${ }^{10}$ F. Feinleib, S. Groves, W. Paul, and R. Zallen, Phys. Rev. 131, 2070 (1963).

"J. D. Wiley, in Semiconductors and Semimetals, edited by R. K. Willard- son and A. C. Beers (Academic, New York, 1975), Vol. 10, p. 91.

${ }^{12}$ F. H. Pollak and M. Cardona, Phys. Rev. 172, 816 (1968).

${ }^{13}$ J. F. Tsay, S. S. Mitra, and B. Bendow Phys. Rev. B 10, 1476 (1974).

${ }^{14}$ K.-H. Goetz, D. Bimberg, H. Jürgensen, J. Solders, A. V. Solomonov, G. F. Glinskii, and M. Razeghi, J. Appl. Phys. 54, 4543 (1983).

${ }^{15} \mathrm{O}$. Berlolo and J. C. Wolley, Proceedings of the 11 th International Conference on Physics Semiconductors, Warsaw, 1972 (Pol. Sci. Publ., Warsaw, 1972), p. 1420.

${ }^{16}$ I. J. Fritz, S. T. Picraux, L. R. Dawson, T. J. Drummond, W. W. Laidig, and N. G. Anderson, Appl. Phys. Lett. 46, 967 (1985).

${ }^{17}$ M. A. Tischler, N. G. Anderson, and S. M. Bedair, Appl. Phys. Lett. 49, 1199 (1986).

\title{
Effects of electron beam injection on ethylene-air combustion
}

\author{
R. M. Gilgenbach, S. W. Bidwell, R. A. Bosch, M. L. Brake, J. E. Tucker, \\ and T. E. Repetti \\ Intense Energy Beam Interaction Laboratory, Nuclear Engineering Department, The University of \\ Michigan, Ann Arbor, Michigan 48109-2104
}

J. A. Sell

Physics Department, General Motors Research Laboratories, Warren, Michigan 48090-9055

\section{(Received 30 March 1987; accepted for publication 2 June 1987)}

\begin{abstract}
Results are presented of the first experiments in which high-current electron beam injection is shown to modify the combustion of both lean and rich ethylene-air mixtures. The rate of pressure rise in the chamber increases by up to a factor of 2 and flame speed increases by $40 \%-$ $50 \%$ for cases in which an electron beam is injected into a spark-ignited nonstoichiometric ethylene-air mixture. Spectroscopic emission from the flame is modified by electron beam injection with more rapid rise and decay of $\mathrm{OH}$ line emission. Further research is needed to identify the cause of the observed enhancement in combustion rate.
\end{abstract}

One of the goals of several groups in combustion physics research is to find methods of increasing flame speed. In an internal combustion engine, for example, higher flame speed in lean mixtures could lead to a higher efficiency. Many different approaches are being pursued, including increasing turbulence, ${ }^{1}$ increasing the concentration of free radicals, ${ }^{2,3}$ and applying electric fields, ${ }^{4}$ and microwaves. ${ }^{5}$ Other approaches involve enhanced ignition such as plasma jet, ${ }^{6}$ torch, ${ }^{7}$ and laser ignition. ${ }^{8,9}$ An approach that seems to be absent from the literature is that of direct injection of energetic electrons into a combustion chamber to stimulate combustion. In the experiment reported here, we present data in which injection of a high-current electron beam ${ }^{10}$ has been demonstrated to dramatically alter the rate of pressure rise, flame speed, and spectroscopic emission in the combustion of both lean and rich ethylene-air mixtures.

The experimental configuration is depicted in Fig. 1. The electron beam is generated by a field emission cathode ${ }^{11}$ on a Febetron generator with peak parameters: $V_{p}=400$ $\mathrm{kV}, I_{p}=1 \mathrm{kA}$, and full width pulse length $=300 \mathrm{~ns}$. A perforated metal screen supports the 0.025 -mm-thick Ti anode foil which is evacuated on the cathode side and undergoes a pressure pulse of several atmospheres from the combustion in the chamber on the opposite side. The anode foil and metal screen reduce the injected current to about $200 \mathrm{~A}$. The interaction chamber is an aluminum cross of circular cross section with an inside diameter of $8.26 \mathrm{~cm}$ and a length of 22 $\mathrm{cm}$ giving a chamber volume of 1.191 . Quartz windows are located at the sides and end of the chamber. A spark plug and piezoelectric pressure transducer are located at the top of the chamber.

Several diagnostics were used to monitor the combustion process. Chamber pressure was measured with a pressure transducer and preamplifier fed into an oscilloscope. Line emission from the $309-\mathrm{nm}$ OH line was measured with a line pass filter coupled to a photomultiplier tube which was oriented transverse to the electron beam. The $\mathrm{OH}$ represents an important intermediate in the splitting of fuel molecules. Since $\mathrm{OH}$ originates primarily from the flame and postflame gases, $\mathrm{OH}$ emission rise and fall times provide an indication of flame speed. For flame front measurements, schlieren photography with two-dimensional resolution was performed transverse to the direction of the electron beam injection by means of a pulsed ruby laser diagnostic described in Refs. 12 and 13. Also, emission spectra were observed both during and after the spark by a $0.275-\mathrm{m}$ spectrograph coupled to a gated optical multichannel analyzer.

The experimental procedure was as follows. Fuel and air were mixed for $30 \mathrm{~s}$ by a small fan located inside the chamber. This mixture was ignited by a conventional sparkignition system; after a $1 \mathrm{~ms}$ delay, the electron beam was injected. This permitted a direct comparison of the modifica- 


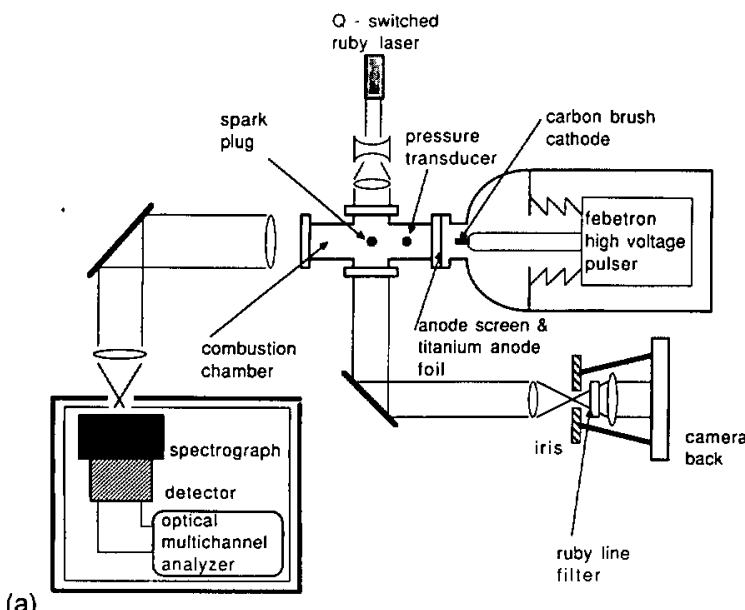

(a)

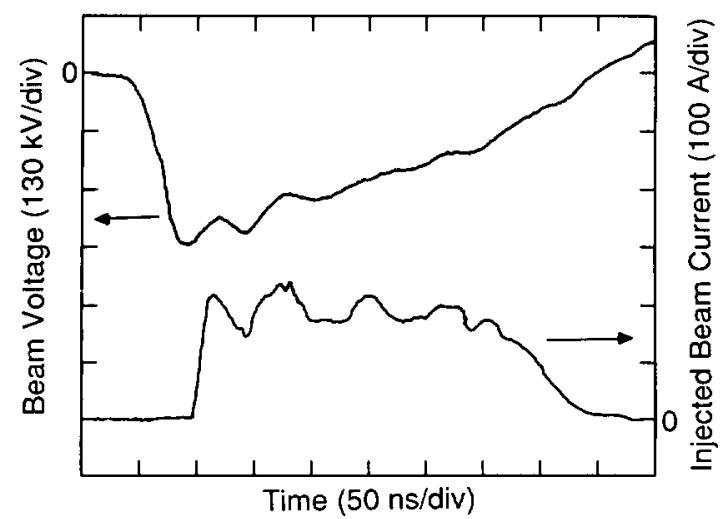

(b)

FIG. 1. (a) Experimental configuration. (b) Cathode voltage and injected beam current for a typical febetron pulse.

tion of combustion parameters by the electron beam.

It should be noted that direct ignition of the mixture by the electron beam did not occur in these experiments. This is undoubtedly due to the low-energy density deposited into the gas by the electrons. The pressure rise was undetectable ( $<1$ Torr) when the electron beam was injected into an unignited mixture. Thus, the electron beam caused negligible temperature increase in the mixture.

Figure 2 presents pressure signals and $\mathrm{OH}$-emission data for combustion of a lean mixture with versus without electron beam injection. These measurements indicate that the combustion process was more rapid with electron beam injection. Figure 3 presents a plot of pressure rise time versus equivalence ratio (where $\phi=1$ corresponds to the stoichiometric fuel-air ratio of 48-Torr $\mathrm{C}_{2} \mathrm{H}_{4}$ and 692-Torr air). The data show about a $50 \%$ decrease in pressure rise time as a result of electron beam injection into lean and rich mixtures, but very little effect near the stoichiometric fuel-air ratio. For the cases where the pressure rise time was reduced, the $\mathrm{OH}$-emission rise time and decay-time were also reduced and the magnitude of the peak pressure was increased by $10 \%-20 \%$. The pressure rise time data was also more reproducible in these cases. The increase in combustion rate was observable with electron beam injection as early as $15 \mathrm{~ms}$ before the spark ignition and as late as $15 \mathrm{~ms}$ after the spark ignition. This more rapid combustion is similar to that observed in laser ${ }^{8,9}$ and plasma jet ${ }^{6,7}$ ignition. Electron beam

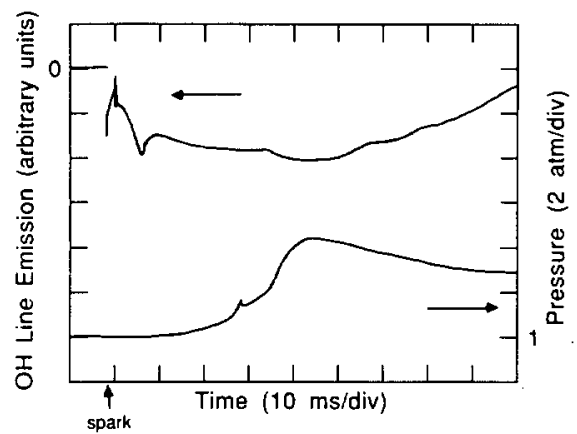

(a)

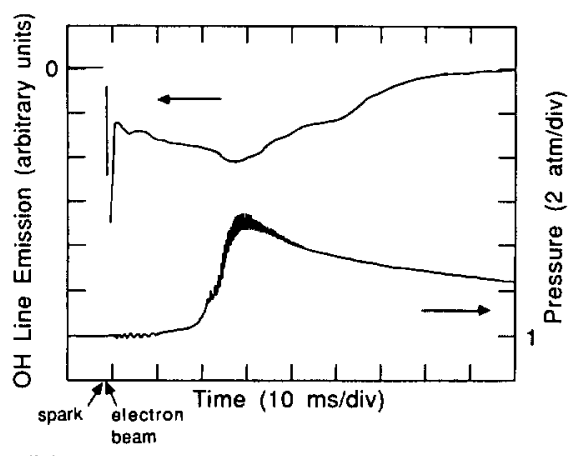

(b)

FIG. 2. Combustion data for lean mixture of 30-Torr $\mathrm{C}_{2} \mathrm{H}_{4}$ and 710-Torr air (equivalence ratio $\phi=0.6$ ). Upper trace: $\mathrm{OH}$ Line emission intensity at $309 \mathrm{~nm}$. (inverted trace). Lower trace: Pressure transducer signal (2 atm/div). (a) Oscilloscope traces for combustion with spark ignition alone. (b) Oscilloscope traces for combustion with electron beam injection $1 \mathrm{~ms}$ after the spark.

injection increased the level of pressure oscillations measured by a microphone (at $1-2 \mathrm{kHz}$ ) during the pressure rise and caused a loud squeal.

Laminar flame propagation was observed using schlieren photographs of the flame front at various times after ignition. In Fig. 4, the distance between the flame front and the spark-plug tip is shown as a function of time for a lean mixture with versus without electron beam injection. For this mixture, the propagation velocity of the flame front was clearly increased by electron beam injection. Electron beam injection appears to enhance the flame speed by up to $50 \%$ for lean mixtures (Fig. 4 ) and $40 \%$ for rich mixtures

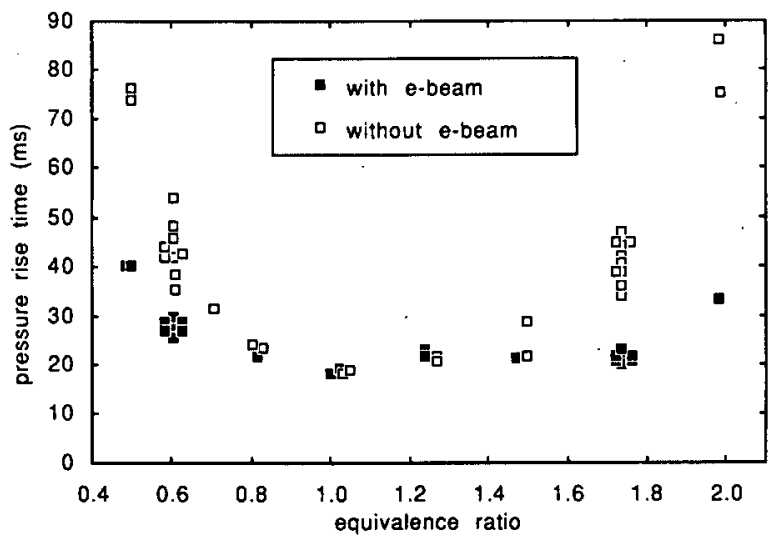

FIG. 3. Pressure rise time (measured from time of spark to pressure peak) as a function of fuel-air equivalence ratio $\phi$. Stoichiometric mix at $\phi=1$ corresponds to 48-Torr $\mathrm{C}_{2} \mathrm{H}_{4}$ and 692-Torr air. 


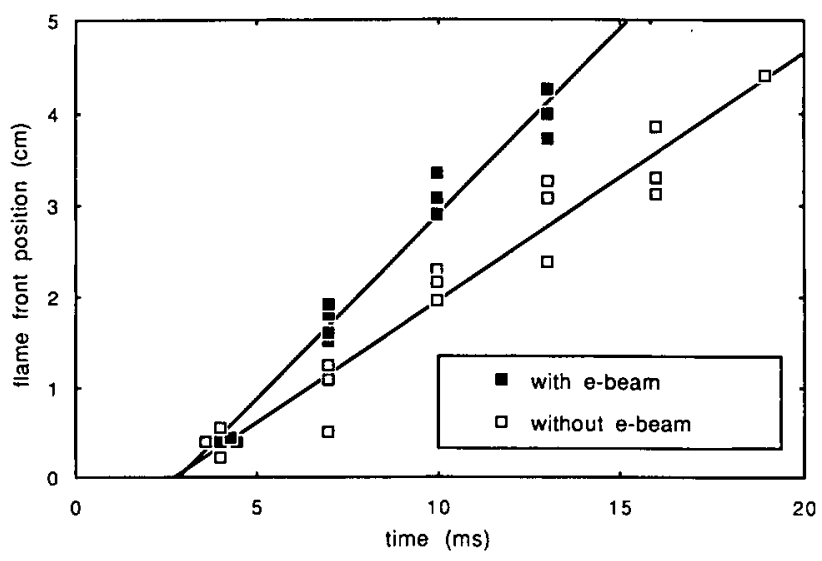

FIG. 4. Flame position transverse to electron beam direction, measured with laser schlieren photography. Data are for a lean mixture with 30-Torr $\mathrm{C}_{2} \mathrm{H}_{4}$ and 710-Torr air $(\phi=0.6)$. From the slope of the lines, the flame speed was determined to be $403 \mathrm{~cm} / \mathrm{s}$ with electron beam injection, and 268 $\mathrm{cm} / \mathrm{s}$ without electron beam injection.

(not shown). In shots with electron beam injection the flame front was slightly elongated transverse to the beam direction compared to nearly spherical flame expansion without the electron beam. This suggests that the flame was propagating more rapidly in the region of the electron beam axis, where the electron beam current density was highest. Consistent with the pressure data, schlieren photography near the stoichiometric ratio showed no distinguishable difference between flame speeds with versus without electron beam injection.

In conclusion, the injection of a 300-ns electron beam pulse is seen to significantly modify the pressure, flame speed, and spectroscopic emission data over time scales exceeding $10 \mathrm{~ms}$. There are a number of physical processes which must be examined for comparison of the relevant time scales. First, during the electron beam pulse, emission spectroscopy shows that the gas becomes a plasma consisting of neutral molecules, singly ionized molecules, and free electrons (both primary and secondary). The electron temperature of this plasma has been determined to be about $1.5 \mathrm{eV}$ from line emission data in experiments in which we substi- tuted argon in place of nitrogen. Other investigators ${ }^{14}$ have studied the dynamics of ionized channels in air. Those results indicate that free electron effects cannot persist for many milliseconds. However, molecular ion effects could persist on these time scales.

Other effects which may influence the combustion process over tens of ms include: (1) electron beam induced turbulence, (2) generation of metastable states, (3) dissociation to produce oxygen or fuel radicals, (4) nonequilibrium vibrational populations and, (5) increased thermal diffusivity, since flame speed is proportional to the square root of this quantity. Determination of the contribution from each of these effects is extremely complicated and will be the subject of future investigations.

We would like to thank Richard B. Hall for technical assistance. This work was supported by the National Science Foundation under a Presidential Young Investigator Award, Grant No. ECS-8351837.

${ }^{1}$ R. G. Abdel-Gayed and D. Bradley, in Proceedings of the International Conference on Fuel-Air Explosions, edited by J. H. S. Lee and C. M. Guirao (University of Waterloo, Montreal, 1982), p. 51.

${ }^{2}$ R. Hickling, General Motors Research Report No. EM-478, September 30, 1980.

${ }^{3}$ T. M. Sloane and J. W. Ratcliffe, General Motors Research Laboratories Publication No. GMR-4404, July 11, 1983.

${ }^{4}$ H. C. Jaggers and A. von Engel, Combust. Flame 16, 275 (1971).

${ }^{5}$ C. S. Maclatchy, R. M. Clements, and P. R. Smy, Combust. Flame 45, 161 (1982).

${ }^{6}$ P. L. Pitt and R. M. Clements, Combust. Sci. Tech. 30, 327 (1983).

${ }^{7}$ P. L. Pitt, J. D. Ridley, and R. M. Clements, Combust. Sci. Tech. 35, 277 (1.984).

${ }^{8} \mathrm{R}$. Hickling and W. R. Smith, Society of Automotive Engineers Paper No. 740114, Allendale, Pennsylvania.

${ }^{9}$ J. A. Sell, General Motors Research Report No. GMR-5247, October 30, 1985 .

${ }^{10}$ R. M. Gilgenbach, S. Bidwell, M. L. Brake, K. Pearce, T. Repetti, and J. E. Tucker, Bull. Am. Phys. Soc. 31, 1430 (1986).

${ }^{11}$ M. L. Brake, R. M. Gilgenbach, R. F. Lucey, Jr., K. Pearce, and T. Repetti, Appl. Phys. Lett. 49, 696 (1986).

${ }^{12}$ L. D. Horton and R. M. Gilgenbach, Phys. Fluids 25, 1702 (1982).

${ }^{13}$ L. D. Horton and R. M. Gilgenbach, Appl. Phys. Lett. 43, 1010 (1983). ${ }^{14}$ D. W. Koopman and K. A. Saum, J. Appl. Phys. 44, 5328 (1973). 